\title{
Ação política e solidariedade na luta contra a impunidade
}

\section{Political action and solidarity fighting impunity}

\author{
Adriana Marcela Bogado \\ Doutora em Sociologia e pesquisadora do Núcleo de Estudos Afro-brasileiros \\ (NEAB/Univ. Federal de São Carlos) \\ adrimarbogado@yahoo.com.br
}

\section{Resumo:}

Neste texto discutimos algumas formas que assume a luta contra os crimes impunes, assim como o processo de empoderamento decorrente desse engajamento. Tomamos como base a trajetória biográfica de Graciela Centurión, que desde 2006 luta por justiça pela morte não esclarecida de sua filha. Esta trajetória foi reconstruída durante uma pesquisa de doutorado em que estudamos a participação política de mulheres em movimentos sociais contemporâneos na Argentina, sob a ótica de suas experiências e memórias.

\section{Abstract:}

In this paper we discuss different ways that the fight against crimes unpunished takes, as well as the empowerment process resulting from the engagement in this fight. We took as base the life histories of Graciela Centurión that, since 2006, fight for justice on the unclear death of her daughter. This trajectory was reconstructed during a doctoral research in which the political participation of women in contemporary social movements in Argentina was studied, from the perspective of these women's experiences and memories.

Keywords: Political action; Impunity;

\author{
Empowerment
}

Palavras-chave: Ação política; Impunidade; Empoderamento 
1 - Uma versão prévia deste texto foi apresentada como comunicação oral no Grupo de Trabalho "História Oral e Movimentos Sociais", durante o "Seminário Internacional NEHO 20 anos. História Oral: Identidade e Compromisso", realizado na Universidade de São Paulo, de 10 a 12 de novembro de 2011.
2 - Ver a matéria "Investigarán a un ex policía por la muerte de su novia" (CLARÍN, 2008).

3 - A pesquisa, financiada pela Fundação de Amparo à Pesquisa do Estado de São Paulo (Fapesp), foi orientada pela Profa. Dra. Maria Aparecida de Moraes Silva e desenvolvida junto ao Programa de Pós-graduação em Sociologia da Universidade Federal de São Carlos (PPGS/UFSCar).
$\mathcal{A}$ luta contra a impunidade é um tipo de mobilização que, principalmente, nas últimas duas décadas, vem ocupando o cenário do protesto social e político na Argentina. Atualmente, são milhares de famílias que lutam contra a impunidade, reivindicam justiça pela morte de seus familiares, se mobilizam para evitar que os crimes não resolvidos pelo sistema judiciário sejam engavetados ou prescrevam, fazem suas próprias investigaçôes, criam associações de auto-ajuda e memória permanente (CARUSO, 2009), e se articulam com diferentes movimentos sociais e organizaçóes locais para que suas demandas sejam atendidas.[1]

Esse tipo de reivindicação, que surge na sociedade civil, encontra diferentes graus de resposta no sistema. Assim, alguns familiares que pedem justiça têm sido recebidos por altos mandatários, como governadores provinciais ou, inclusive, a atual Presidenta da Nação, Cristina Kirchner. Também, em 2003, foi criado o Programa Nacional Anti-impunidade, atual Programa Nacional de Luta contra a Impunidade, vinculado ao Ministério de Justiça da Nação, visando atender os familiares das vítimas. Para trabalhar nesse programa foram contratados alguns familiares considerados emblemáticos devido a sua luta por justiça. Apenas nesse programa continuavam ativos 1.415 casos, considerados a ponta do iceberg. (CARUSO, 2009)

A lentidão do sistema judiciário, a falta de equidade, entre os acusados e as vítimas, e a impunidade são as principais falhas do sistema. De acordo com a Organização das Naçôes Unidas (ONU), a Secretaria de Direitos Humanos define impunidade como:

[...] a ausência de acusaçóes criminais a autores de violaçóes dos direitos humanos, assim como de sua responsabilidade civil, administrativa ou disciplinária. Há impunidade quando o indivíduo escapa a qualquer investigação tendente a sua imputação, prisão, julgamento e, se comprovada sua culpa, a receber uma punição apropriada para o crime cometido. Esse ciclo só acaba quando se reparam os danos sofridos pelas vítimas. (SECRETARIA DE DIREITOS HUMANOS, s/d)

Neste texto, analisamos algumas formas que assume a luta contra a impunidade, tomando como base a trajetória biográfica de Graciela Centurión que, desde 2006, luta para que a morte de sua filha caçula seja esclarecida. Em 17 de agosto de 2006, sua filha, Mariana Victoria Sánchez, foi ferida a bala no carro do namorado, o agente de polícia Gabriel Omar García, enquanto estavam no estacionamento de restaurante fast food, em Campana (Província de Buenos Aires). A jovem morreu horas mais tarde num hospital. $\mathrm{O}$ promotor de justiça, considerando o testemunho do namorado, registrou o caso como suicídio e declarou-o como testemunha.[2] Graciela questionou essa narrativa legal e, apontando aspectos confusos e contraditórios, construiu uma narrativa da resistência e começou a lutar para que a morte da filha não ficasse impune.

Sua trajetória foi reconstruída no marco de uma pesquisa de doutorado em que estudamos a participação política de mulheres em movimentos sociais contemporâneos na Argentina, a partir de suas experiências e memórias.[3] Utilizamos como metodologia a História Oral e a Observação Participante, e, nesse mesmo contexto, realizamos um registro imagético e pesquisa documental em 
alguns jornais regionais e nacionais.

A trajetória de Graciela possibilita abordar algumas formas que assume a luta contra a impunidade, apontar suas características, identificar continuidades com outras mobilizaçóes do campo popular e suas próprias (re)criaçóes. Também, permite identificar o processo de empoderamento decorrente do engajamento nessa luta, contribuindo com a discussão a respeito dos movimentos sociais e outras formas de ação coletiva.

Inicialmente, apresentamos o perfil de Graciela e destacamos algumas características de sua narrativa, fruto do trabalho com a metodologia História Oral. Em seguida, referimos o início de sua ação política, caracterizamos as formas de protesto que utiliza para veicular sua reivindicação, para, finalmente, refletir sobre seu processo de empoderamento. Cabe mencionar que optamos por manter os depoimentos em espanhol, sem modificar o estilo nem corrigir as expressóes utilizadas, muitas delas próprias da linguagem coloquial. Assim, dentro dos limites da escrita, tentamos conservar alguns traços da expressividade própria da oralidade.

\section{“SiEMPRE UNA VIDA TRANQUILA, BUENO, RELATIVAMENTE TRANQUILA"}

Graciela nasceu em 1961, em Recife, interior da Província de Buenos Aires. Ainda criança, quando os pais se separaram, mudou-se com sua mãe para San Fernando. Aos 17 anos abandonou o ensino médio para se casar. Teve dois filhos: Pablo e Mariana. Quando a última nasceu mudaram-se para um bairro de periferia urbana em Garín, a $39 \mathrm{~km}$ de Buenos Aires. Durante a entrevista, confessou que, inicialmente, "no me gustaba nada [a cidade], calle de tierra, los colectivos que estaban lejos”.

Durante muitos anos trabalhou como boleira e era conhecida no bairro por ter feito os bolos de batismo, aniversário, comunháo, casamento etc., de muitos vizinhos. Quando os filhos "cresceram", retomou os estudos e concluiu o ensino médio. Também, realizou cursos de pintura e desenho artístico. Posteriormente, estudou o Professorado de Artes Visuais. Na época da pesquisa estava próxima a se formar e já trabalhava como professora, dando aulas em escolas da regiáo.

Se formos considerar toda sua narrativa, o crime (como é considerada por ela a morte da filha) adquire um caráter estruturador, pois é a partir dele que se organiza a narração. (CALDEIRA, 2000) Em vários momentos é possível identificar o uso de marcas temporais "después de lo que nos pasó, con mi hija", que remetem a esse caráter estruturador do crime e que, como acontecimento marcante, envolve um antes e depois. Assim, também se encontram marcadores como "estaba mi hija todavía". A narrativa do crime evidencia o intuito de reorganizar um universo de vida, em virtude de que um novo significado é dado ao bairro, à cidade, aos vizinhos. (CALDEIRA, 2000) A solidariedade e apoio recebidos fazem com que Graciela se sinta parte de uma comunidade e, portanto, sem interesse de cortar esse vínculo, após ter sofrido o impacto do crime.

“[...] mis hijos se criaron acá, a los dos le encantaba, ¿no? Fijáte Pablo vino de seis años y fijáte a él le encanta este lugar, a él le gusta. Ojo, a mí también ahora, creo que yo, después de lo que nos pasó, con mi hija y después de haber tenido apoyo de tanta gente, pero de tanta gente, tanta gente, tanta gente que nos ayudó creo que 
no me iría del lugar [se emociona], viste.” [Graciela, 13 de dezembro de 2008, Garín]

A entrevista de História Oral criou um momento para recordar, do latim re-cordis, voltar a passar pelo coração. Assim, diversas emoçóes afloraram durante nossas conversas. Desfrutando do rememorar, a narradora se detinha em minúcias do cotidiano, relacionadas à filha como, por exemplo, a repetição do mesmo cardápio a cada domingo. Nas lembranças enxergava-se a si mesma, através do olhar de admiração e orgulho que sua filha tinha pelo fato dela estudar.

"[...] yo venía de mis clases y ella, feliz de lo que yo hacía. Ella decía, bueno mi mamá, siempre, lo dijo delante de mí: Mi vieja sabe hacer de todo. Cuando se casa una de sus amigas le decía: Decíle a mi mamá que te diga cómo podés hacer los centros de mesa, para que no pagara viste [com sonriso, riso da pesquisadora]. [...] Pero siempre te decía: Mi mamá sabe hacer de todo.” [Graciela, 13 de dezembro de 2008, Garín]

Um dos momentos mais emocionantes da entrevista se suscitou enquanto discorria sobre aspectos de sua vida como estudante e até tinha suscitado o riso da pesquisadora diante do "medo" da prova final. Aos poucos, seu relato tornou-se denso e manifestou um sentimento de frustração, pois, como aluna, não conseguira realizar como pretendia a preparação para um bom exame final. Contou que, no dia anterior à entrevista, apresentou-se para o exame final, "Creo no, no quería entrar: una porque no había alcanzado a estudiar, a leer, me parecía que ella (a professora) no se merecía que no haya terminado". A voz da narradora vai se embargando, enquanto confessa o quanto lhe custou se apresentar, e se entristece ao dizer que foi uma das disciplinas que abandonou por um tempo, após a morte da filha. Em uma pausa pequena, enquanto tenta conter o pranto, o cachorro se aproxima dela e com a carícia costumeira, Graciela lhe faz um mimo e se desculpa: "Él, lloro y siempre viene conmigo". E afirma emocionada e com firmeza que também foram essas disciplinas que a fizeram seguir enfrente, "Y bueno, y hoy gracias a eso también estoy trabajando".

Lembra que foi pelo apoio recebido dos/as colegas, que conseguiu retomar o curso. Eles ligavam, visitavam-na, a levavam para assistir às aulas, "medio me arrastraban hasta el colectivo, viste. Y bueno después ya, después lo hacía sola [...] porque era como que si no me ocupaba en algo más, creo que me iba a volver loca”.

A trajetória em pauta permite identificar elementos importantes para pensar em trajetórias sociais e no impacto de eventos marcantes sobre as mesmas. Battagliola et al. (1991), definindo trajetória como o encadeamento temporal das posiçóes sucessivamente ocupadas pelos indivíduos nos diferentes campos do espaço social destacam que os acontecimentos marcantes (como neste caso a morte de um membro da família) causam uma inflexão na mesma e é preciso desenvolver estratégias de rattrapage (recuperação dos danos, recobramento).

É importante apontar que a própria noção de trajetória implica deslocamentos em um espaço sujeito a múltiplas transformaçôes. Portanto, nas trajetórias não existe linha reta com tempos sucessivos nem predeterminados, senão 
que os indivíduos ocupam simultaneamente diferentes posiçóes constituindo um conjunto de itinerários. Nesse sentido, observamos que articular seus itinerários de vida é o "jeito" que Graciela encontrou para continuar em frente, e isso caracterizará inclusive suas formas de protesto. Como aponta Javier Auyero, seguindo as reflexôes de MacAdam, as trajetórias sociais moldam os protestos assim como estes moldam as biografias das pessoas. (AUYERO, 2004: 260)

Contudo, no caso de Graciela, a via do protesto náo foi sua primeira alternativa. Inicialmente, ela percorre a via do sistema. Assim, no dia seguinte à morte da filha, vai procurar o promotor de justiça, mas é tratada com descaso. Lembra:

"Entro preguntando por el fiscal y el tipo, como si el fiscal fuera el rey, me dice que el fiscal no estaba y que quién era yo. $\mathrm{Y}$ entonces le empiezo a decir: 'Me mataron a mi hija', 'Bueno señora, siéntese allá y espereló'. [Ela]: ¿Cómo siéntese allá y espereló?, ¡¿Dónde está el fiscal?! [...] Y el tipo con una soberbia me decía eso y yo bueno, me puse loca, le dije que a mí me habían matado a mi hija. Le digo: ¿Cómo se ve que a vos no te mataron tu hija!” [Graciela, 13 de dezembro de 2008, Garín]

Passaram-se três meses do falecimento da filha, trocaram o advogado e o processo judicial quase foi arquivado, "ahí ya me empezaron a golpear de todos lados, a decirme: Graciela hay que actuar, tenés que salir, y que fue lo que hice” (grifo nosso). A partir do incentivo de pessoas próximas começou a percorrer a via do protesto. Comenta que uma vizinha, participante da Corrente Classista Combativa (CCC), [4] ofereceu-lhe o apoio do movimento para fazer uma marcha. Confessa: "Para mí fue terrible, la primer marcha fue terrible, salí a hablar con todo el mundo". A convocação foi divulgada, também, no jornal regional $L a$ Auténtica Defensa, solicitando a concentração das pessoas em frente ao Fórum de Campana, no dia 18 de dezembro de 2006, às 11 h30min., sob a reivindicação "Justiça para Mariana Sánchez".

Graciela não tinha participação política anterior, e esclarece que costumava dizer que de política não sabia nada, nunca tinha estado em uma marcha, e não sabia como fazê-la. O coordenador da CCC lhe disse que levaria um alto-falante e que ela iria falar [Fig. 1]. Mas, "Yo no sabía muy bien cómo encarar todo. Y bue-

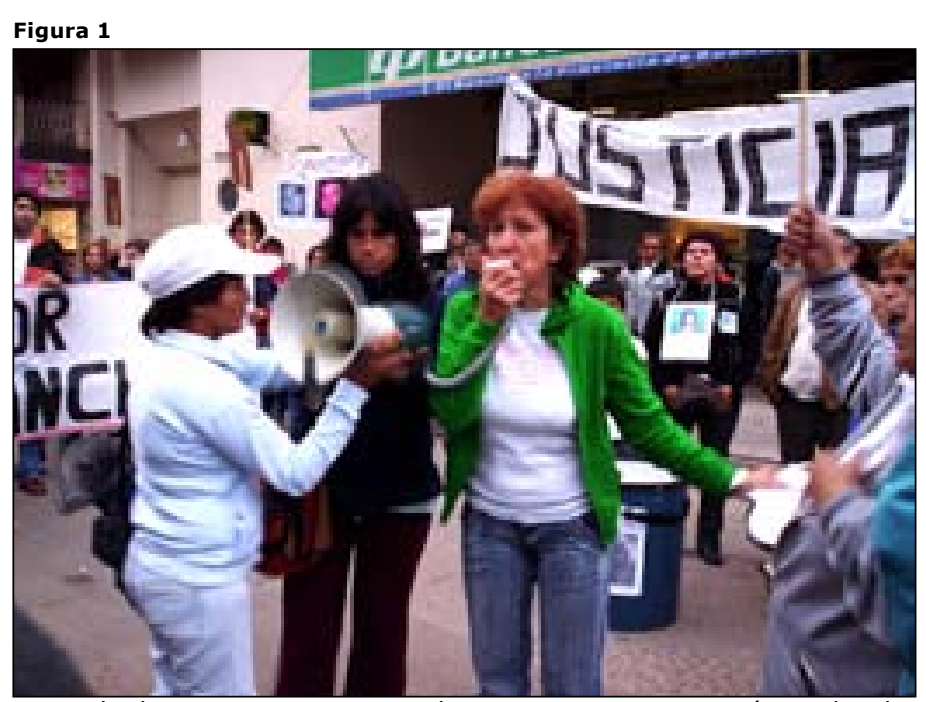

Graciela dirige-se aos presentes durante passeata em Garín, realizada em 20 de abril de 2007.

Fonte: <http://elgarinense.blogspot.com/2007_04_22_archive.htm/>
4 - A Corrente Classista e Combativa (CCC) é uma organização político-sindical surgida em 1994, ligada ao Partido Comunista Revolucionário (PCR). Seu surgimento está vinculado a um contexto marcado pelas difíceis condições de vida das classes operária e popular, assim como pelas lutas contra as políticas neoliberais implementadas na década de 1990. 
no, alguien hizo una carta, las amigas de mi hija, que hasta el día de hoy me acompañan”. Assim, a partir de um evento que impacta na trajetória familiar e, principalmente, pelo fato de ver que o crime poderia ficar impune, começa a desenvolver um itinerário político.

Um aspecto fundamental para salientar é que, embora ela manifestasse que não sabia fazer uma marcha, porque nunca tinha participado de uma, sua ação não partia do zero, em virtude de que, na Argentina, a memória coletiva é povoada de imagens de mobilizaçóes, principalmente, fornecidas pela mídia. As marchas das Mães e das Avós da Praça de Maio e outras organizações de direitos humanos assim como informaram ao "público sobre distintas formas de entender a opressão", também forneceram e fornecem modelos de resistência e luta. (BERGMAN e SZURMUK, 2006: 256) Nesse último sentido, estabeleceram um dos paradigmas legitimados de atuação das mulheres no campo da política, a partir do uso social e político da maternidade.

Nesse sentido, também, cabe mencionar três mobilizaçóes que, durante a década de 1990, canalizaram na forma de protestos a indignação popular e exigência de justiça para os crimes impunes, revelando novas formas de açáo coletiva. Em oito de setembro de 1990, a jovem María Soledad Morales foi assassinada por filhos de funcionários do governo da Província de Catamarca. Sua morte despertou o pedido de justiça da comunidade, que iniciou as "Marchas do Silêncio”. Finalmente, os assassinos foram presos e uma coalizáo opositora continuou ganhando as eleiçóes, acabando com um caudilho regional. Segundo Bergman e Szurmuk (2006), a partir do caso de María Soledad, "outros casos de homicídios que envolvem mulheres jovens na Argentina têm produzido respostas coletivas entre os cidadãos que têm aprendido a 'ler nas entrelinhas' as versóes oficiais dos fatos e a desafiar as mesmas instituiçóes que supostamente os protegem”. (BERGMAN e ZSURMUK, 2006: 268, grifos nossos)

Outro crime que ganhou visibilidade nacional foi o do jovem soldado Carrasco do Regimento de Zapala (Província de Neuquén), vítima da violência militar. Os superiores encobriram o crime e disseram a sua família que ele tinha desertado. Em seis de abril de 1994, seu cadáver foi encontrado dentro da área militar. As mobilizaçóes reivindicando justiça influíram também, na eliminação do serviço militar obrigatório. Em 31 de janeiro de 1996, foram julgados e condenados pelo crime, um subtenente e dois soldados. O terceiro crime, que ainda motiva protestos, foi o de José Luis Cabezas, fotógrafo da revista Noticias, assassinado em 25 de janeiro de 1997. Na reconstrução dos fatos, o tribunal e o fiscal coincidiram em que Cabezas foi assassinado por seu empenho em fotografar o empresário Alfredo Yabrán, acusado de chefiar uma máfia vinculada ao poder.

Geralmente, essas mobilizaçóes contra a impunidade tiveram como força impulsora as mulheres, que em seus diferentes papéis de mãe, esposa, amiga, familiar, vizinha criaram uma primeira rede de solidariedade e, uma vez na cena pública, estabeleceram articulaçôes com outros movimentos e organizaçôes e/ou procuram o apoio de representantes do governo. Nesse sentido, um dos aspectos que consideramos chave na primeira mobilização realizada por Graciela foi a solidariedade de gênero que se manifesta, inicialmente, na conversa entre vizinhas, e se abre em redes de solidariedade envolvendo amizades, colegas, familiares, moradores/as do bairro e participantes da CCC. Mais tarde, articula-se com reivindicaçóes por justiça em nível nacional ao longo do engajamento de Graciela. (BOGADO, 2010: 243) 
No texto "A morte de Chandra", Ranajit Guha salienta a força de uma "solidariedade alternativa" entre as mulheres, marcada pela experiência de gênero e motivada pela empatia. (GUHA, 2003) Nesse sentido, uma participante da CCC, que acompanhou as mobilizaçóes de Graciela, dizia: "Hay que entenderla a ella también, ¿`sabés qué que te maten a un hijo?”. Essa afirmação reflete a solidariedade que nasce da empatia e, também, a legitimação da luta que possibilita torná-la pública. Se não surge essa solidariedade, é difícil pensar em mobilização e ação política. Contudo, Graciela comenta que, assim como muitas pessoas acompanharam-na em sua reivindicação por justiça, há amigas da filha que não, "Que no quisieron estar porque le tenían miedo a la policía".

Segundo Enrique Rajchenberg (2002), o terrorismo de estado deixou marcas profundas na sociedade: desaparecimentos e assassinatos; saldo econômico pela abertura ao neoliberalismo, e um terceiro saldo concernente à história do mesmo processo ditatorial. Reflexo dos efeitos do terrorismo de estado é a paralisia da capacidade crítica da sociedade e da ação. (RAJCHENBERG, 2002: 75-76)

Graciela comenta que tinham lhe advertido que nas marchas haveria policiais infiltrados e que passaria a ser "vigiada" pela polícia. Ela vinculava esse tipo de ação a outro momento histórico, assim refletia: "vos decís pero eso es, no sé, de otra época", referindo-se ao período da ditadura militar no país. Porém, não é apenas o medo, o controle e a opressão que nos remetem ao processo ditatorial, senão também as formas de resistência e luta que passam a ser utilizadas pela nossa entrevistada, como veremos no item a seguir.

\section{"MI VIEJA SABE HACER DE TODO"}

Neste item, vamos apontar as diferentes formas que Graciela utilizou para canalizar sua reivindicação e as articulaçóes com os outros itinerários de sua trajetória pessoal. São intervençóes no espaço público com o intuito que as pessoas conheçam o caso, o crime, a situação de injustiça e, posteriormente, como afirmou na entrevista, o sucesso da mobilização.

Em setembro de 2007, enquanto desenvolvíamos o trabalho de campo, tivemos a oportunidade de acompanhar um dos protestos liderados Graciela junto a participantes da Corrente Classista Combativa (CCC), no Fórum de Campana. $\mathrm{O}$ registro imagético que realizamos [Fig. 2] traz à tona as performances das organizaçóes de direitos humanos como, por exemplo, quando ela mesma ou seus familiares portam fotografias de Mariana.

Graciela também se vale do escrache, forma de protesto criada em dezembro de 1996, pela organização de direitos humanos H.I.J.O.S. (Filhos

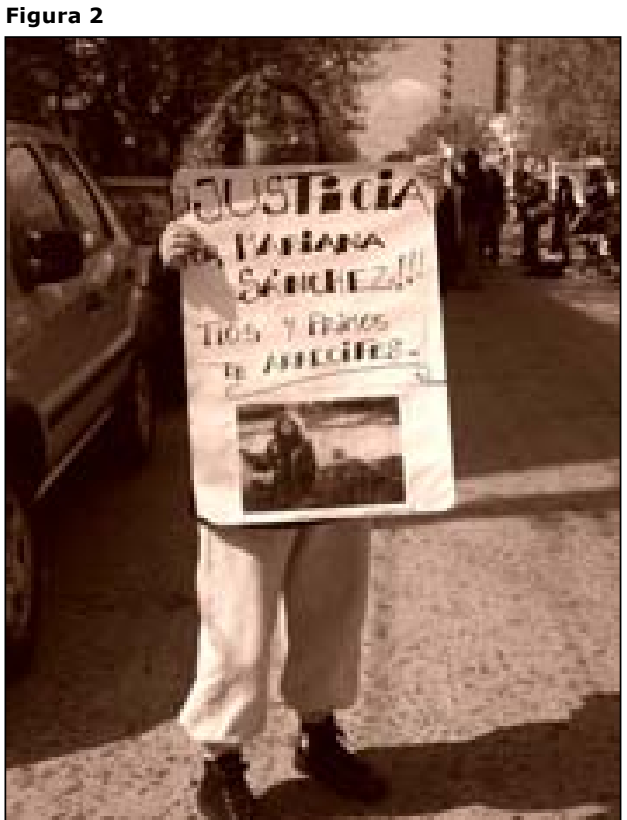

Familiar de Mariana durante protesto no Fórum de Campana. Fotografia produzida pela pesquisadora, setembro de 2007. 


\section{Artigos \& Ensaios}

pela Identidade, a Justiça, contra o Esquecimento e o Silêncio). O escrache constitui uma ação simbólica, não violenta, de reivindicação por justiça e surge como forma de condenação popular dirigida aos repressores da última ditadura militar. Contudo, seu uso se estendeu a outros alvos, como pessoas vinculadas a casos de corrupçáo, de autoritarismo policial e de tudo que seja considerado como atentado contra os direitos individuais e/ou coletivos. (CATELA, 2001: 360)

No caso de nossa entrevista, seu alvo principal era o promotor de justiça dr. Marcelo Pernisi, que considerava a morte da filha como suicídio. Como a ênfase do escrache está vinculada aos lugares de pertencimento, Graciela realizava os escraches no local de trabalho do promotor: o Fórum de Campana, onde está o processo da filha. [Fig. 3] Mas, também, lhe aconteceu de encontrar Gabriel Omar García na rua. Em uma dessas ocasióes:

"Le empecé a gritar asesino, ¿qué hiciste?, viste [...] Me decía, hasta lo desconocía de las cosas que me decía el tipo. Era una basura, era evidentemente una basura, le dije de todo. No sabés me salió el odio, lo corri". [Graciela, 13 de dezembro de 2008, Garín]

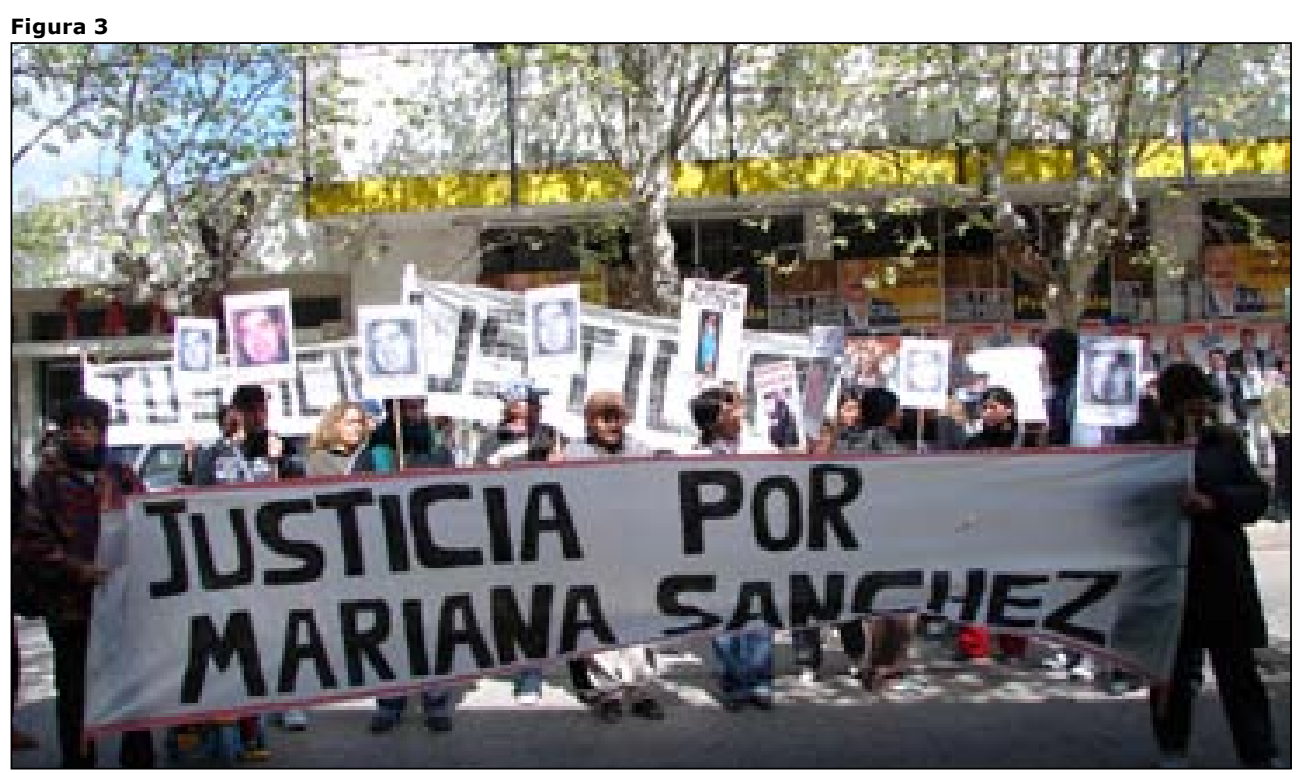

Manifestantes durante protesto no Fórum de Campana. Fotografia produzida pela pesquisadora, em setembro de 2007.

Em outra oportunidade, gritou, insultou-o, mas, também começou a distribuir os folhetos que divulgavam o acontecido entre as pessoas que estavam próximas. Dessa forma sua ação foi adquirindo o perfil do escrache.

Há mais uma forma utilizada por Graciela para veicular sua reivindicação, que lembra as práticas das organizaçôes de direitos humanos. Trata-se da "solicitada", um tipo de texto de caráter "comercial" (pago e de particulares), que costuma aparecer em jornais para veicular informaçóes, opinióes e até algum tipo de denúncia ou manifestação de caráter político. [Fig. 4] Cabe apontar que a publicação de solicitadas foi (e continua sendo, como pode ser apreciado na imagem a seguir) um recurso utilizado por familiares de pessoas desaparecidas no período da última ditadura militar.

Segundo Catela (2001), trata-se de "suportes da memória" que lembram mediante a imagem física a pessoa desaparecida ao mesmo tempo em que vei- 
Figura 4

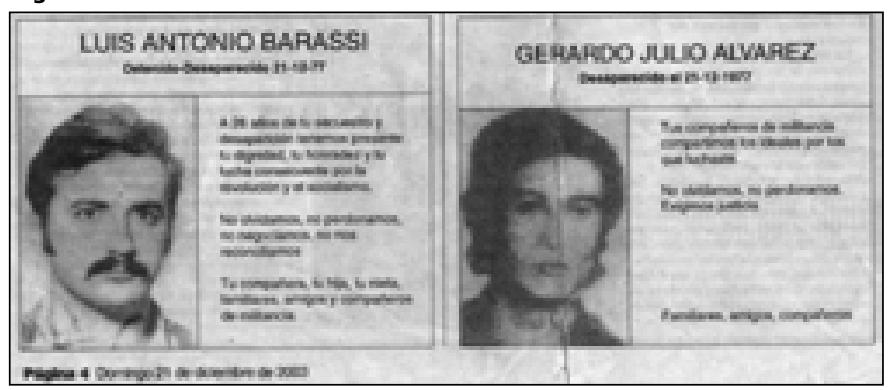

Exemplo de solicitadas publicadas no jornal Página 12.

culam uma denúncia e, também, constituem uma espécie de "oferenda" de culto à pessoa desaparecida. Essas publicações tinham a função de reatualizar a memória coletiva, projetando no tempo e no espaço, inscriçôes através das quais o público poderia "perpetuar a lembrança dessa pessoa”. (CATELA, 2001:189)

Graciela é ciente desse efeito e, de fato, explicita que como o crime da filha ficou conhecido como "el caso de la chica del McDonald's" foi dessa forma que publicaram as convocatórias e outras informaçóes sobre o caso, "para que quedara grabado". Por outro lado, sabe o quanto incomoda uma publicação desse tipo e até recebeu algumas advertências para ter cuidado com o que falava. Contudo, considera que é muito importante que as pessoas saibam que as mobilizaçóes deram resultado. Assim, em uma das últimas solicitadas

"[...] decíamos cómo después de haber hecho todo lo que hicimos esa persona que era testigo se lo iba a indagar, ¿no? Y está acusado de homicidio [...] Y bueno que la gente supiera que todo lo que hicimos, hasta donde nosotros llegamos fue por algo y que era la verdad la que nosotros decíamos y la que ellos intentaban ocultar." [Graciela, 13 de dezembro de 2008, Garín]

As mobilizaçóes de Graciela também incorporaram elementos do movimento piqueteiro, considerando que foi a Cor-

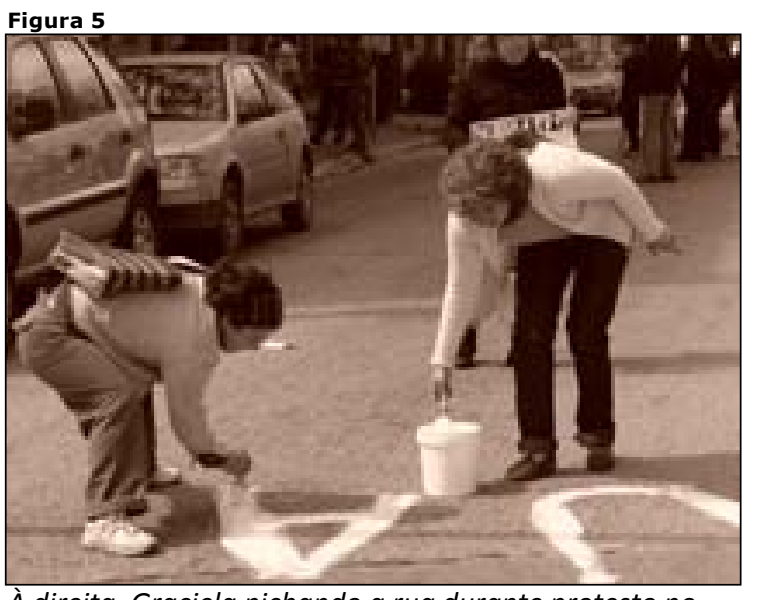

À direita, Graciela pichando a rua durante protesto no Fórum de Campana. Fotografia produzida pela pesquisadora, em setembro de 2007. rente Classista Combativa que apoiou sua reivindicação por justiça. Na mobilização que acompanhamos no Fórum de Campana [Fig. 5], observamos o característico "piquete" (corte do trânsito). Durante a concentração, enquanto esperavam a chegada de outras organizaçōes, dois grupos de jovens se alternavam tocando tambores e caixas [Figs. 6 e 7], as pessoas se juntavam em pequenas rodas de chimarráo e conversavam, outras colavam os panfletos no chão, 


\section{Artigos \& Ensaios}
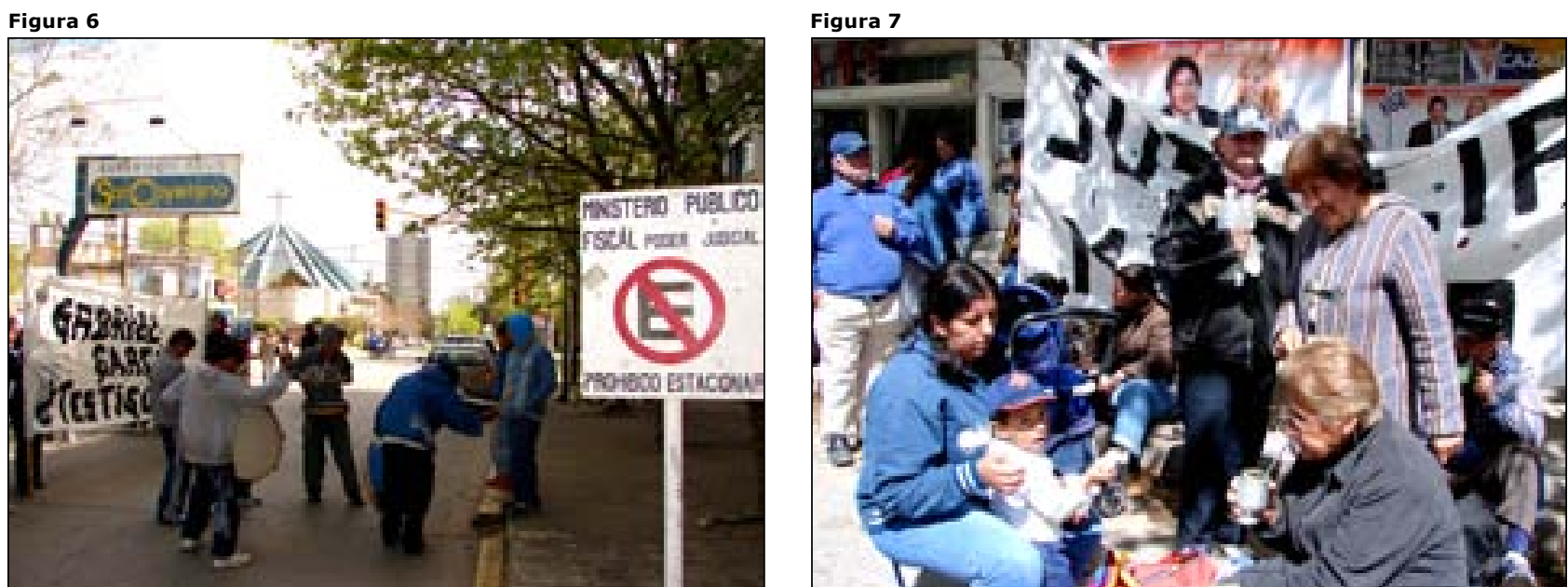

Manifestantes durante protesto no Fórum de Campana. Fotografia produzida pela pesquisadora, emsetembro de 2007.

Figura 8

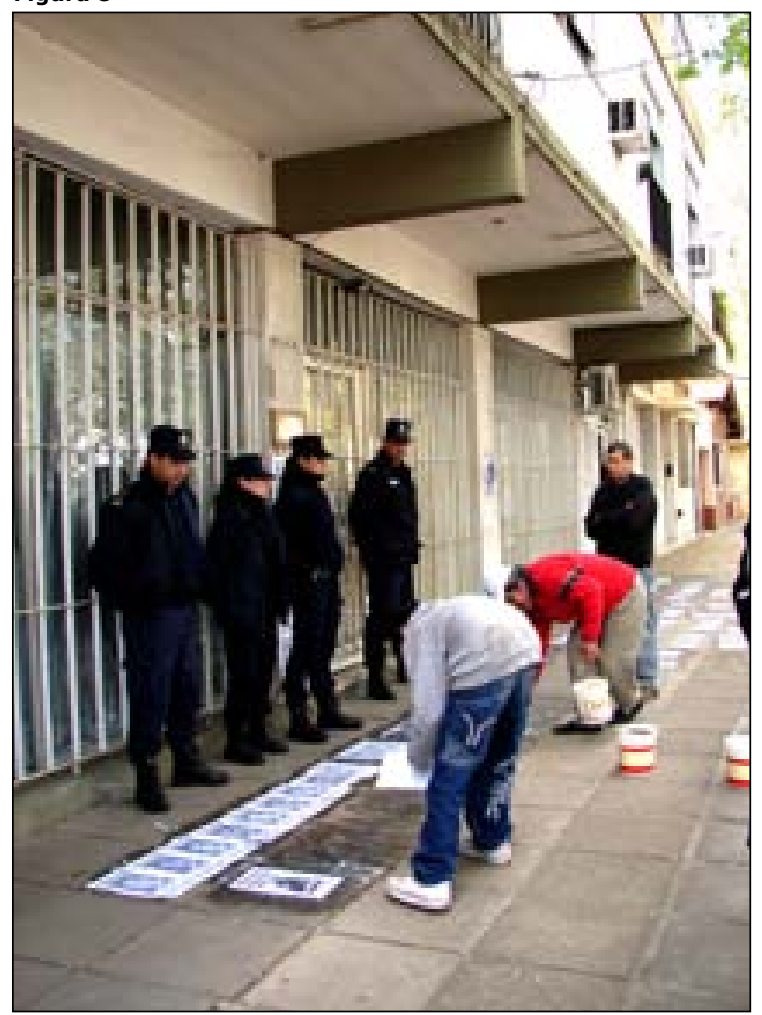

Manifestantes colando panfletos na entrada do Fórum, frente ao olhar da polícia. Fotografia produzida pela pesquisadora, em setembro de 2007. em postes, em placas etc., frente ao olhar de meia dúzia de agentes da polícia [Fig. 8] que "cuidavam" da entrada do Fórum, enquanto Graciela pichava nas ruas a palavra "justiça”.

Todas essas açóes aconteciam simultaneamente, criando um espaço social, pois além de ocupar um território determinado, múltiplas interaçóes aconteciam.

Assim que terminara de pintar as ruas, Graciela se colocou de frente aos manifestantes, os tambores pararam e ela começou a falar. Todos acompanharam seu discurso com atenção, respeito e sentimento. Precisamente, é a presença do discurso que nos permite caracterizar sua atuação como ação política (ARENDT, 2007). Segundo a pensadora, devido à pluralidade humana, condição de toda vida política, ação e discurso são indispensáveis para que haja entendimento mútuo. $\mathrm{Na}$ ação e no discurso "os homens mostram quem são, revelam ativamente suas identidades pessoais e singulares, e assim apresentam-se ao mundo humano" (ARENDT, 2007: 192). Separar a ação do discurso implica destituir a primeira de seu caráter de revelaçáo e, portanto, de seu sujeito.

Sem discurso, a ação deixaria de ser ação, pois não haveria ator; e o ator, agente do ato, só é possível se for, ao mesmo tempo, o autor das palavras. A ação que ele inicia é humanamente revelada através de palavras; e, embora o ato possa ser percebido em sua manifestação física bruta, sem acompanhamento verbal, só se torna relevante através da palavra falada na qual o autor se identifica, anuncia o que fez, faz e pretende fazer. (ARENDT, 2002: 191)

Quando acabava o discurso, Graciela era aplaudida pelos manifestantes e alguns transeuntes que tinham se aproximado para ouvir. Em seguida, alguns jornalistas se aproximavam para entrevistá-la e, após disso, ela se retirava junto aos 
manifestantes.

Outra forma que encontrou para veicular sua reivindicação reflete as articulaçóes com outros itinerários de sua trajetória pessoal. Trata-se de intervençóes no espaço público com o intuito de que as pessoas conheçam o caso, o crime, a situação de injustiça e, posteriormente, como afirmou, o sucesso da mobilização. Comenta que muitas vezes, entre uma marcha e outra, tinha a sensaçáo de que nada acontecia, e sentiu a necessidade de "dejar un sello". Assim, elaborou uns panfletos e começou a colá-los no Fórum, todas as noites, aproveitando os intervalos das aulas do Professorado: "Iba a clases, salía de una corrida y pegaba todo eso, y volvía a clases, viste. Y así creo que me sostuvo un poco eso también, ¿no?”. Esses panfletos espalharam-se pelos comércios do bairro e da cidade (e, alguns, ainda permanecem colados), viajaram em ônibus, ficaram nas mãos de transeuntes etc., tinham a dupla função de divulgar o caso da filha, com uma foto dela ou do namorado e o nome do promotor de justiça, e também de denunciar o crime impune.

Finalmente, gostaríamos de assinalar o processo de empoderamento que a narrativa de Graciela reflete. De acordo com a definição de Iorio (2002), o empoderamento é um processo em que pessoas ou grupos que possuem uma parcela pequena de poder e, portanto, vêem limitadas e/ou anuladas suas possibilidades de escolha, decisão e ação, adquirem parcelas maiores de poder que lhes permitem o exercício de uma cidadania mais plena. Cabe destacar que se trata de um processo não linear, com avanços e recuos, e é "moldado para cada indivíduo ou grupo através de suas vidas, seus contextos e sua história” (DEERE e LEÓN, 2002: 55).

Segundo explicou-nos, houve várias situações em que nossa entrevistada foi intimidada pela polícia e sentiu muito medo. No começo de sua mobilização representantes do Centro de Proteção à Vítima (CPV) aconselharam-lhe ter cuidado com sua segurança, e explicaram-lhe que seria vigiada, “Cómo me van a seguir?, decía yo, si yo no hice nada. 'Ellos te van a seguir, te van a presionar, te van a querer asustar'. Y fue tal cual”.

\footnotetext{
"[...] creo que cada cosa que me hizo dar miedo y por ahí no dormir en la noche, porque me he pasado noches, los primeros días no paraba de temblar del miedo. Así como tuve mucho miedo, después tuve mucho valor y dije: Hijos de mil puta, los voy a denunciar a donde vaya y en cada marcha que voy, doy el nombre del hijo de mil puta y empiezo por el fiscal.” [Graciela, 13 de dezembro de 2008, Garín]
}

Inicialmente, ela se sente sem poder, sente medo, mas a partir do protesto, começa a descobrir seu poder político (SCOTT, 1998), no sentido de que sua reivindicação mobiliza outras pessoas, consegue reuni-las e é capaz de encabeçar uma marcha. Percebe que a ação coletiva e pública confronta a subrepticia, "si él tiene tanto poder yo también puedo juntar mucha gente, ¿me entendés?". Em todo esse processo, Graciela descobriu que "la justicia es la burocracia nada más, no la podés tocar y vos la tenés que llevar adelante", sendo capaz de golpear portas, denunciar e "discutir si es necesario con el fiscal, acusarlo, porque ellos no son seres superiores a nosotros. Acusarlos, porque son delincuentes también, algunos".

Enuncia, assim, sua crítica ao sistema, à forma com que opera a justiça, e as vicissitudes que enfrenta quem decide que um crime náo deve ficar impune. Nes- 
se sentido, salienta o assessoramento e apoio recebidos do CPV, frente ao descaso e à ineficiência judicial. Sua experiência de luta resultou no ensejo de criar alguma organização contra impunidade. Atualmente, Graciela espera o julgamento.

\section{CONSIDERAÇÓES FINAIS}

A trajetória de Graciela permite caracterizar um tipo mobilização que faz parte do atual cenário do protesto na Argentina e, também, dar visibilidade à participação política das mulheres, suas formas de organização e luta, muitas vezes invisibilizadas. Por um lado, é possível identificar certa continuidade com as formas de protestos de organizações de direitos humanos e a própria influência do movimento piqueteiro, particularmente com a CCC da Zona Norte, organização que apóia suas mobilizaçôes. Mas, também, sobressai a recriação de outras formas de veicular sua reivindicação por justiça, como o uso da solicitada e o panfleto. Sua atuaçáo política conjuga a via do sistema e a via do protesto, e revela que há múltiplas formas e espaços "potencialmente" disponíveis para a ação política.

O trabalho com a metodologia da História Oral possibilitou reconstruir sua trajetória, refletindo não apenas o passado e situação atual, senão também a projeção em relação ao futuro, assim como a dialética dos itinerários de vida familiar, profissional e político.

Além do medo e dos ressaibos que ficaram do terrorismo de estado, uma comunidade foi mobilizada. Consideramos que, não apenas, pela capacidade de convocação que pode ter uma mãe que exige justiça, senáo também porque as pessoas consideraram que se tratava de uma reivindicação justa. Foi esse apoio que tornou possível a luta de Graciela e que lhe deu legitimidade e visibilidade política.

\section{REFERENCLIAS BIBLIOGRÁFICAS:}

ARENDT, Hannah. A Condição Humana. Rio de Janeiro: Forense Universitária, 2007.

BATTAGLIOLA, Françoise; BERTAUX-WIAME, Isabelle; FERRAND, Michelle; IMBERT, Françoise. Dire sa Vie: Entre Travail et Famille. La Construction Sociale des Trajectoires. Paris: CSU, 1991.

AUYERO, Javier. Vidas Beligerantes. Dos Mujeres Argentinas, Dos Protestas y la Búsqueda de Reconocimiento. Buenos Aires: Universidad Nacional de Quilmes, 2002.

BERGMAN, Marcelo; SZURMUK, Mónica. Memoria, Cuerpo y Silencio: El caso "Maria Soledad" y la Demanda de Ciudadania en la Argentina de los Noventa. Acta Poética 27 (2), otoño, 2006. Disponível em: <http://132.248.101.214/ html-docs/acta-poetica/27-2/bermszur.pdf >. Acesso em: 25 set. 2012.

AUTORA. Tecendo a política. "Itinerários de participação política de mulheres em movimentos contemporâneos na Argentina”. 2010. Tesis (Doutorado) Programa de Pós-graduação em Sociologia, Universidade Federal de São Carlos, São Carlos. Disponível em: < http://200.136.241.56/htdocs/tedeSimplificado/tde_busca/arquivo.php?codArquivo=3186>. Acesso em: 25 set. 2012.

CALDEIRA, Teresa P. D. R. Cidade de Muros: Crime, Segregação e Cidadania em São Paulo. São Paulo: Ed.34/ Edusp, 2000.

CARUSO, Liliana. Dolor Sobre el Dolor: Hay 1.415 Crimenes que Aún Siguen 
Impunes. Clarín, 28 jun. 2009. Disponível em: <http://edant.clarin.com/diario/2009/06/28/policiales/g-01947901.htm>. Acesso em: 25 set. 2012.

CATELA, Ludmila. Situação-limite e Memória: A Reconstrução do Mundo dos Familiares de Desaparecido da Argentina. São Paulo: HUCITEC e ANPOCS, 2001.

CLARIN. Investigarán a un ex policía por la muerte de su novia. 16 fev. 2008. Disponível em: <http://www.clarin.com/diario/2008/02/16/policiales/g-06301. htm>. Acesso em: 25 set. 2012.

DEERE, Carmen D.; LEÓN, Magdalena. O Empoderamento da Mulher. Direitos à Terra e Direitos de Propriedade na América Latina. Porto Alegre: Editora da UFRS, 2002.

GUHA, Ranajit. La muerte de Chandra. Sobre excesos y exabruptos, $\mathrm{N}^{\circ} 12$, Ano 2, Jul. 2003. Disponível em: <http://www.vivilibros.com/excesos/12-a-04. htm>. Acesso em 25 set. 2012.

IORIO, Cecília. "Algumas consideraçóes sobre estratégias de empoderamento e de direitos”. In: ROMANO, Jorge O.; ANTUNES, Marta. Empoderamento e Direitos no Combate à Pobreza. Rio de Janeiro: Action Aid Brasil, 2002, p.21-44.

RAJCHENBERG, Enrique. La rebelión de la memoria. Entrevista con Mauricio Fernández Picolo. Chiapas, México D.F., Nº13, 2002, p.75-86.

SECRETARIA DE DERECHOS HUMANOS. Programa Nacional de Lucha contra La Impunidad. Disponível em: <http://www.derhuman.jus.gov.ar/ pronalci.html>. Acesso em 25 de set. 2012.

SCOTT, Joan. A Invisibilidade da Experiência. Projeto História, São Paulo, N ${ }^{\circ}$ 16, fev. 1998, p. 297-325. 